EFFECT OF AGING ON THE SAFETY AND SENSITIVITY OF

NITROGLYCERIN/NITROCELLULOSE MIXTURES

P. C. Hsu, G. Hust, M. Zhang, J. Reynolds, R. Schmidt

March 19, 2013 
This document was prepared as an account of work sponsored by an agency of the United States government. Neither the United States government nor Lawrence Livermore National Security, LLC, nor any of their employees makes any warranty, expressed or implied, or assumes any legal liability or responsibility for the accuracy, completeness, or usefulness of any information, apparatus, product, or process disclosed, or represents that its use would not infringe privately owned rights. Reference herein to any specific commercial product, process, or service by trade name, trademark, manufacturer, or otherwise does not necessarily constitute or imply its endorsement, recommendation, or favoring by the United States government or Lawrence Livermore National Security, LLC. The views and opinions of authors expressed herein do not necessarily state or reflect those of the United States government or Lawrence Livermore National Security, LLC, and shall not be used for advertising or product endorsement purposes.

This work performed under the auspices of the U.S. Department of Energy by Lawrence Livermore National Laboratory under Contract DE-AC52-07NA27344. 


\title{
Effect of Aging on the Safety and Sensitivity of Nitroglycer- ine/Nitrocellulose Mixtures
}

\author{
Peter C. Hsu, Gary R. Hust, Mao Xi Zhang, John G. Reynolds, and Robert D. Schmidt \\ Energetic Materials Center \\ Lawrence Livermore National Laboratory, Livermore, CA USA
}

March \#\#, 2013

\begin{abstract}
Mixtures of nitroglycerine (NG) and nitrocellulose (NC) were prepared and aged for several days. Smallscale safety and thermal (SSST) tests were conducted to determine the effect of aging on impact, friction, spark and thermal sensitivities of the mixtures. Nuclear magnetic resonance (NMR) was also used to determine any possible chemical reaction and products occurred during the aging process. The test results are summarized in this report.

The main effect due to aging is on impact sensitivity, found by this study. Depending upon how the drop hammer test was performed, the sensitivity of the NG/NC material either decreased or increased with aging. BAM friction also possibly showed a slight decrease in sensitivity upon aging. ESD, DSC, and NMR exhibited no changes.

Keywords: Explosives, impact sensitivity, drop hammer, friction sensitivity, spark sensitivity, nitroglycerine, nitrocellulose, DSC, NMR.
\end{abstract}




\section{INTRODUCTION}

Mixtures of nitroglycerin (NG) and nitrocellulose (NC) are important for some specific applications. Since the mixtures may not be used right after formulation, it is beneficial to understand whether sensitivity is changed upon aging, which may compromise safe handling. This report presents the test results of the NGNC mixtures before and after aging with standard techniques used at LLNL and other laboratories (LANL, SNL, IH and Tyndall) in which explosives are studied.

\section{METHOD}

Small-scale sensitivity testing was done to determine material response to various stimuli including impact, friction, static spark and thermal. NMR was also used to analyze for the presence of reaction products if any chemical reaction would occur during the aging process. The SSST tests, briefly described below, provide parameters for determining safe handling practices.

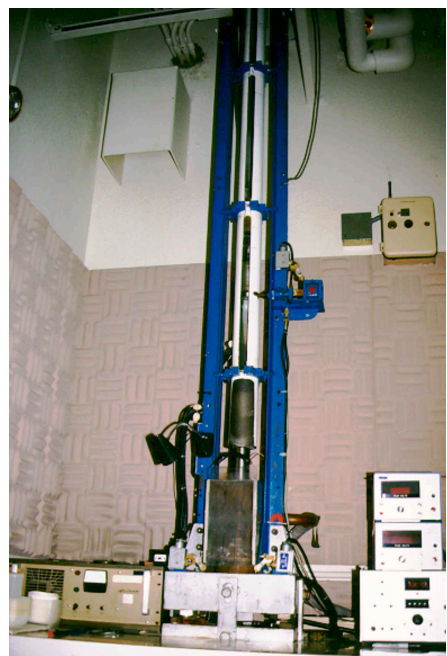

Figure 1. Drop Hammer at LLNL

\subsection{Drop Hammer (impact sensitivity)}

ERL Type 12 drop hammer equipment at LLNL, shown in Figure 1, was used to determine the impact sensitivity [1]. The equipment includes a $2.5-\mathrm{kg}$ drop weight, a striker (upper anvil, $2.5 \mathrm{~kg}$ for solid samples and $1.0 \mathrm{~kg}$ for liquid samples), a bottom anvil, a microphone sensor, and a peakmeter. For each drop, a sample (35 mg for solids or 35 microliter for liquids) is placed on the bottom anvil surface and impacted by the drop weight from different heights. Signs of reactions upon impact are observed and recorded. These signs may include noises, flashes or sparks, smoke, pressure, gas emissions, temperature rise due to exothermic reaction, color change of the sample, and changes to the anvil surface (noted by inspection). For solid samples, a "GO" was defined as a microphone sensor (for noise detection) response of $\geq 1.3 \mathrm{~V}$ as measured by a peakmeter. The higher the $\mathrm{DH}_{50}$ values, the lower the impact sensitivity. The method used to calculate $\mathrm{DH}_{50}$ values is the "up and down" or Bruceton method [2,3]. PETN and RDX have impact sensitivities of 15 and $22 \mathrm{~cm}$, respectively (powder samples), as measured at LLNL on this apparatus. TATB has impact sensitivity more than $177 \mathrm{~cm}$, which is the maximum drop height on the LLNL instrument. For liquid samples, a "GO" was determined by the noise levels as measured by the peakmeter, appearance of flashes, temperature rise of the anvil, and visual inspection of the anvil surface. For reference, liquid explosives TMETN and FEFO have impact sensitivities of 14 and $32 \mathrm{~cm}$, respectively.

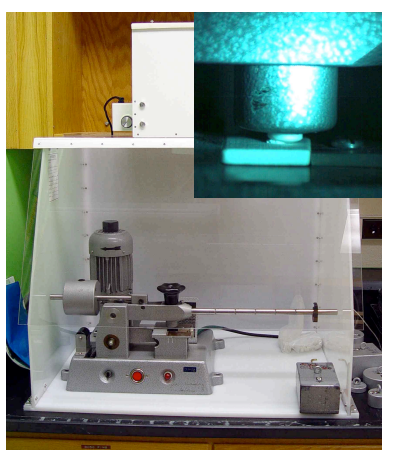

Figure 2. BAM Friction at LLNL

\subsection{Frictional Sensitivity}

A BAM friction sensitivity test machine, as shown in Figure 2, was used to determine the frictional sensitivity [4]. The system uses a fixed porcelain pin and a movable porcelain plate that executes a reciprocating motion. A weight affixed to a torsion arm allows for a variation in applied force between $0.5 \mathrm{~kg}$ to $36.0 \mathrm{~kg}$. The relative measure of the frictional sensitivity of a material is based upon the smallest load $(\mathrm{kg})$ at which reaction occurs for a 1-in-10 series of attempts. The lower the load values, the higher the frictional sensitivity. PETN has a frictional sensitivity of $6.4 \mathrm{~kg}$. 


\subsection{Spark Sensitivity}

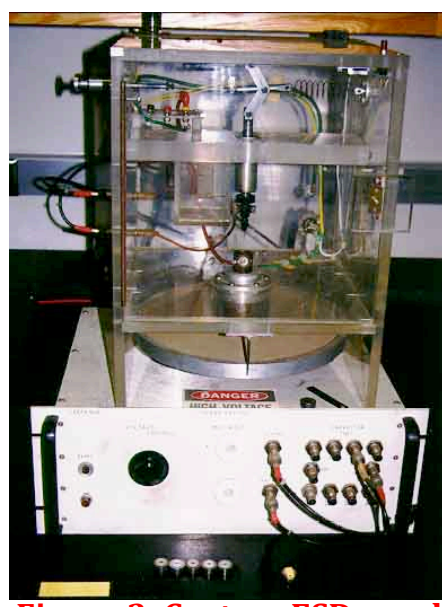

Figure 3. Custom ESD spark Machine at LLNL
The static spark machine at LLNL is used to evaluate the electrostatic discharge hazards (from human electrostatic discharge (ESD)) associated with the handling of explosives [5]. The machine was custom-built almost 30 years ago and consists of a capacitor bank (up to 20,000 pF), a voltage meter, and a discharge circuit, as shown in Figure 3. An adjustable resistor up to $510 \mathrm{ohms}$ (chosen to simulate the electrical resistance of the human body) is wired to the discharge circuit. A 5-mg sample is placed in a Teflon washer sealed to a steel disc and covered with a Mylar tape. High static voltage (up to $10 \mathrm{kv}$ ) is applied and discharged to the sample. Evidence of reaction is judged from the condition of Mylar tape, evolution of smoke, and color change of the sample. Voltage, capacitance, and resistance can be adjusted to achieve the desired static energy. The results obtained are expressed as a zero-in-10 or one-in-ten at a specific voltage and joules. One reaction in ten trials at $\leq 0.25$ joules is considered spark-sensitive. Primary explosives show reaction at $\leq 0.1$ joule.

New ABL spark test equipment, as shown in Figure 4, was procured in 2010. The system is more powerful than the existing custom built systems and is capable of discharging static energy up to $38 \mathrm{~J}$ and down to $10 \mathrm{~mJ}$. Figure 4 shows the new spark tester. The resistance in the discharge circuit can be set at 3 levels $(0$ ohms, 50 ohms, or $510 \mathrm{ohms}$ ). The new spark tester provides greater flexibility for testing different explosives. A gas detector is connected to the new spark tester to monitor the gas emission $\left(\mathrm{CO}_{2}, \mathrm{CO}\right.$, and $\left.\mathrm{NO}_{\mathrm{x}}\right)$ from the testing. When a spark reaction occurs, sudden increases in the concentrations of $\mathrm{CO}_{2}, \mathrm{CO}$, and $\mathrm{NO}_{\mathrm{x}}$ are seen if mole-

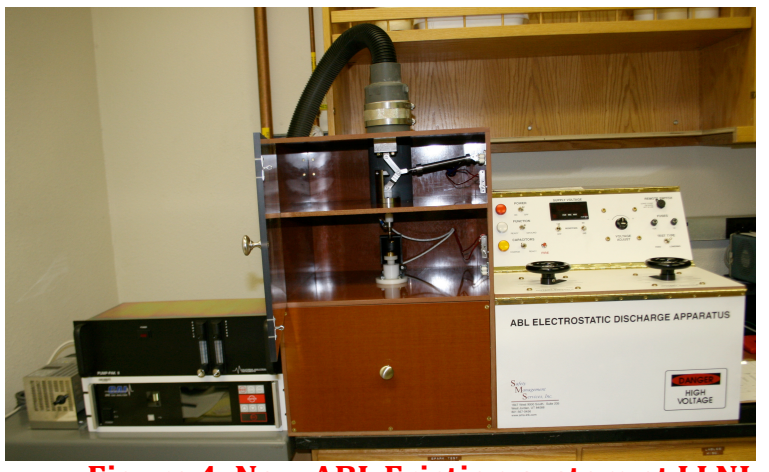

Figure 4. New ABL Friction system at LLNL cules of test sample consist of organic carbon and organic nitrogen (e.g. TNT). The gas detector provides the operator a good tool to judge a spark reaction.

\subsection{Thermal (DSC) Sensitivity}
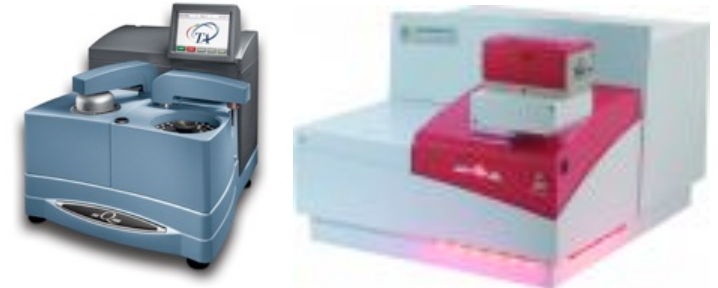

Figure 5. TA DSC and Setaram DSC at LLNL

Thermal testing was performed by differential scanning calorimetry (DSC). The standard system at LLNL is the TA Instrument Q 2920. For volatile liquid samples, the Setaram Sensys DSC is used with a sealed sample holder, which minimizes endothermic features due to volatilization. Figure 5 shows these systems. For the standard configuration, a small amount of sample, usually less than $1 \mathrm{mg}$, is placed in the sample holder and the sample is heated at a constant heating rate of $10^{\circ} \mathrm{C} / \mathrm{min}$. The heat flow is monitored in and out of the sample and presented as a function of temperature. The usual expression of results is temperature of maximum evolution $\left(\mathrm{T}_{\max }\right)$ associated with an exothermic heat flow $\left(\Delta \mathrm{H}_{\text {exo }}\right)$ and a temperature of minimum evolution $\left(\mathrm{T}_{\min }\right)$ associated with an endothermic heat flow $\left(\Delta \mathrm{H}_{\text {endo }}\right)$. An exothermic event is usually associated with an energetic release (indicating a possible energetic material) and an endothermic event is usually associated with a phase change (such as a melt). 


\subsection{Sample preparation}

Because pure NG is sensitive to impact, it is normally diluted with an inert solvent (e.g., acetone, alcohol) for the safety during storage and shipping. This dilution solvent must be removed from NG before formulation, which typically is done either by bubbling dry air through the liquid, or by evaporation from an open container, until a constant weight is achieved. Similarly, dry NC is a highly flammable solid that ignites easily and burns explosively, and typically is shipped and stored with a wetting liquid such as isopropanol, which must be removed by evaporation prior to use.

The NG used in this experiment was obtained from the Copperhead Chemical Co., Inc., as a 60:40 (by weight) mixture of NG in acetone, lot number J-XE5-01. This mixture also contained 1\% (by weight, relative to NG) of 2-nitrodiphenylamine (2-NDPA) as a stabilizer. NC (11.3\% nitrogen) was manufactured by the Nitro Química Co. (São Paulo, Brazil), and procured through Scholle Chemical Co., Inc., lot number 7402. For both NG and NC, the volatile solvent was removed by placing the material in an open container located in a fume hood, and allowing the solvent to evaporate until a constant weight was observed. Table 1 shows the record of removing solvents from NG and NC. Constant weights were observed after 7 days, NG and NC having lost $38.83 \%$ and $11.74 \%$ of their initial weights, respectively.

Pure NC was weighed into a glass container, and pure NG was slowly added to the NC powder using a dropper. The entire surface of the NC was wetted with NG, after which the NG percolated throughout the NC with even wetting. The mixture was gently stirred and tamped to remove air bubbles. Initially, the mixture has a texture similar to wet sand, and the $\mathrm{NC}$ particles are distinct from the NG liquid. After mixing, the NC slowly dissolves into the NG, over a period of several days, eventually creating a nearly transparent, gumlike material.

Four NG/NC mixtures--numbered 1, 2, 3 and 4-were formulated. Mix 1 was tested immediately, and Mix 2 through Mix 4 were allowed to age for different amounts of time before for testing. In addition, mixtures 1 , 2 and 4 were retested at different time. Table 2 shows the mixture compositions, and the times of mixture preparation and tests.

Table 1. Evaporation records of NG solution and wet NC solid

\begin{tabular}{|l|l|l|l|l|}
\hline Time, hour & $\begin{array}{l}\text { NG-acetone so- } \\
\text { lution weight }\end{array}$ & $\begin{array}{l}\text { \% weight loss } \\
\text { NG-acetone so- } \\
\text { lution }\end{array}$ & $\begin{array}{l}\text { NC-isopropanol } \\
\text { mixture weight }^{2}\end{array}$ & $\begin{array}{l}\text { \% weight loss } \\
\text { NC-isopropanol } \\
\text { mixture }\end{array}$ \\
\hline 0 & 53.1896 & 0 & 28.1380 & 0 \\
\hline 4.5 & 48.4665 & 8.8797 & 26.8445 & 4.5970 \\
\hline 124.5 & 32.5325 & 38.8367 & 24.7970 & 11.8736 \\
\hline 128.8 & 32.5333 & 38.8352 & 24.8092 & 11.8303 \\
\hline 176.4 & 32.5378 & 38.8268 & 24.8341 & 11.7418 \\
\hline
\end{tabular}

1. tare weight NG container, $26.3792 \mathrm{~g} ; 2$. Tare weight NC container, $37.8881 \mathrm{~g}$

Table 2. Description of four NG/NC solutions and time of tests

\begin{tabular}{|l|l|l|l|l|}
\hline Mix & 1 & 2 & 3 & 4 \\
\hline NG/NC wt. ratio & $80.60 / 19.40$ & $81.13 / 18.87$ & $80.40 / 19.60$ & $80.92 / 19.08$ \\
\hline $\begin{array}{l}\text { Time of prepara- } \\
\text { tion }(\mathrm{t}=0)\end{array}$ & $10: 3012 / 11 / 12$ & $10: 1012 / 11 / 12$ & $10: 1412 / 11 / 12$ & $10: 1712 / 11 / 12$ \\
\hline Testing Time, hour & $\begin{array}{l}1 \text { to } 6 ; 49 \text { to } 54 ; \\
145 \text { to } 150\end{array}$ & 22 to $30 ; 672$ & 70 to 75 & 214 to $221 ; 1344$ \\
\hline
\end{tabular}

1. NG contains 1 to $2 \%$ NDPA by wt. 


\subsection{NMR Sample Preparation}

Materials.

The $90 \mathrm{MHz}$ NMR spectrometer in B191 was used to obtain spectra at ambient temperature. Ethyl methacrylate in $\mathrm{CDCl}_{3}$ was used to modify NMR parameters for the quantitative analysis. The settings used were: pulse width $=4.2 \mu \mathrm{s}$, relaxation time $=10 \mathrm{~s}$, and scan number $=32$. These give proton integration of the methacrylate $\mathrm{CH}_{3}$ as $0.99, \mathrm{CH}_{2}$ as 0.98 , and $\mathrm{CH}$ as 1.00 , close to the ratio of $1: 1: 1$. The setting was used in all analysis. The chemical shift of tert-butyl group $(\delta 1.432)$ of trinitro-3,5-dimethyl-tert-butylbenzene (TDTB, Aldrich, K\&K Laboratories, Lot\#: 30378L, [note book number MZ10-31-8]) was used as internal standard for the quantitative analysis. Deuterated acetonitrile $\left(\mathrm{CD}_{3} \mathrm{CN}\right.$, Aldrich, 99.8\% D, Lot\#: 13229DP, [notebook number MZ10-31-9]) was used as the solvent and its signal from residue $\mathrm{CH}_{3} \mathrm{CN}$ as the internal standard for chemical shift calibration. The NMR of NG, NC, and 2-nitrodiphenylamine (2-NDPA) were also run separately in $\mathrm{CD}_{3} \mathrm{CN}$. An integration range between 5.0-4.6 ppm was selected for NG quantitative analysis. The samples were weighted on digital balance, error $\pm 0.1 \mathrm{mg}$.

Preparation of samples for NMR analysis.

Preparation of TDTB reference solution: $0.5231 \mathrm{~g}$ of TDTB was dissolved in $20.086 \mathrm{~g}$ of $\mathrm{CD}_{3} \mathrm{CN}$. This gave a TDTB concentration of $2.54 \mathrm{wt}$ \% [MZ10-31-8]. This reference solution was kept in sealed bottle for use. Preparation of NG/NC mixture samples: The NG/NC mixture (40-130 mg) was weight into a vial (Although it would have been preferable to weigh directly into the NMR tube, the mixture is too sticky to do so). Then reference solution [MZ10-31-8] (0.5000-0.6000 g) was added to the vial, which was then gently shaken to dissolve the NG/NC mixture. The resulting homogeneous solution was transferred to NMR tube using a pipette and capped tightly for analysis.

\section{RESULTS}

\subsection{Impact, Friction and ESD analyses of aged mixtures}

Table 3. Sensitivities of NG/NC mixtures and selected high explosives

\begin{tabular}{|c|c|c|c|c|c|}
\hline Sample & $\begin{array}{l}\text { Aging time, } \\
\text { range, } h^{a}\end{array}$ & $\begin{array}{c}\mathrm{DH}_{50}, \mathrm{~cm} \\
\text { bare anvil }\end{array}$ & $\begin{array}{c}\mathrm{DH}_{50}, \mathrm{~cm}, \\
\text { sand paper, }\end{array}$ & Friction, $\mathrm{kg}^{\mathrm{e}}$ & Spark, $\mathrm{J}^{\mathrm{f}}$ \\
\hline $\operatorname{Mix} 1^{\mathrm{g}}$ & 1 to 6 & 7.6 & 4.7 & $1 / 10 @ 8.4$ & $1 / 1 @ 9.4$ \\
\hline $\operatorname{Mix} 1^{\mathrm{g}}$ & 49 to 54 & 15.2 & 2.1 & $\mathrm{NT}^{1}$ & $\mathrm{NT}^{1}$ \\
\hline $\operatorname{Mix} 1^{\mathrm{g}}$ & 145 to 150 & $\mathrm{NT}^{1}$ & 2.4 & $1 / 10 @ 12.0$ & $\mathrm{NT}^{1}$ \\
\hline $\operatorname{Mix} 2^{\mathrm{h}}$ & 22 to 30 & 14.5 & 2.5 & 1/10@12.4 & $\mathrm{NT}^{1}$ \\
\hline $\operatorname{Mix} 2^{\mathrm{h}}$ & 672 & $\mathrm{NT}^{1}$ & 2.2 & & $\mathrm{NT}^{1}$ \\
\hline $\operatorname{Mix} 3^{i}$ & 70 to 75 & 14.4 & 2.5 & $1 / 10 @ 16.4$ & $\mathrm{NT}^{1}$ \\
\hline $\operatorname{Mix} 4^{j}$ & 214 to 221 & 15.0 & 2.0 & $1 / 10 @ 12.4$ & $\mathrm{NT}^{1}$ \\
\hline $\operatorname{Mix} 4^{j}$ & 1344 & $\mathrm{NT}^{1}$ & $\mathrm{NT}^{1}$ & $\mathrm{NT}^{1}$ & $0 / 10 @ 1.3^{\circ}$ \\
\hline PETN & & & 15 & $1 / 10 @ 6.4$ & $0 / 10 @ 1.0^{\circ}$ \\
\hline HMX & & & 32 & 1/10@11.6 & $0 / 10 @ 1.0^{\circ}$ \\
\hline TATB & & & $>177^{\mathrm{m}}$ & $0 / 10 @ 36^{\mathrm{n}}$ & $0 / 10 @ 1.0^{\circ}$ \\
\hline $\mathrm{NG}^{\mathrm{k}}$ & & 9.1 & & 1/10@9.6 & $0 / 10 @ 1.0^{\circ}$ \\
\hline
\end{tabular}

a. Approximate times, see Table 2 for exact times; b. $\mathrm{DH}_{50}$, in $\mathrm{cm}$, by modified Bruceton method, height for $50 \%$ probability of reaction; c. sample placed on bare anvil; d. sample placed on 120-grit Si/Carbide wet/dry sandpaper; e. Next level above threshold level (TIL) where positive initiation is detected; (TIL is the load (kg) at which zero reaction out of ten trials with at least one reaction out of ten trials at the next higher load level; f. Next level above threshold level (TIL) where positive initiation is detected; (TIL is the load (J) at which zero reaction out of ten trials with at least one reaction out of ten trials at the next higher load level; g. notebook number PCH-XIII-104-1; h. notebook number PCH-XIII-1042; i. notebook number PCH-XIII-104-3; j. notebook number PCH-XIII-104-4; k. contains 1 wt. \% 2-NDPA as measured by manufacturer; 1 . not tested; $m$. no sensitivity to impact; $n$. no sensitivity to friction; 0 . no sensitivity to spark. 
The four NG/NC mixtures were prepared (mixed) on the same day. Mixtures 1, 2, 3, and 4 were tested on the same day, after one day, after 3 days and after 9 days, respectively for impact sensitivity, friction sensitivity, spark sensitivity, DSC analysis, and NMR analysis. The test results are listed in Table 3. Sensitivity data for four other commonly used explosives are also listed in the table for comparison.

- Drop Hammer Test Results. For the ESL Drop Hammer tests, a small sample (35 mg) of the gel was precisely measured and placed on the bottom anvil surface (with or without 120-grit sandpaper) for impact sensitivity testing. Table 3 shows that the four NG/NC mixtures were all impact-sensitive when tested on the 120-grit sandpaper. The $\mathrm{DH}_{50}$ was $4.7 \mathrm{~cm}$ when it was freshly prepared and then decreased to about $2.0 \mathrm{~cm}$ after aging for several days. When tested on a bare anvil surface, $\mathrm{DH}_{50}$ for the 4 mixtures was about $15 \mathrm{~cm}$ regardless of time of aging except for Mix $1(7.6 \mathrm{~cm})$.

- BAM Friction Test Results. Friction sensitivity data for 4 mixtures tested at different times were about $12 \mathrm{~kg} \pm 4.0 \mathrm{~kg}$, which is similar to the friction sensitivity of HMX. Mixture 1 is more sensitive than the older samples indicating that aging may reduce friction sensitivity.

- ESD Test Results. When tested with the ABL spark tester and set the resistance at 0 Ohms, no spark initiation was observed until static energy was increased to 9.4 Joules. Figure 6 shows the sample picture taken after spark testing at 9.4 Joules. Scorch marks are apparent, but at the high energy used to generate this reaction, the mixtures were considered not spark sensitive so further testing was not performed except for Mix 4. Mix 4 was tested at energy 1.3 Joules at 0 Ohms after 56 days, but no spark reaction was observed.

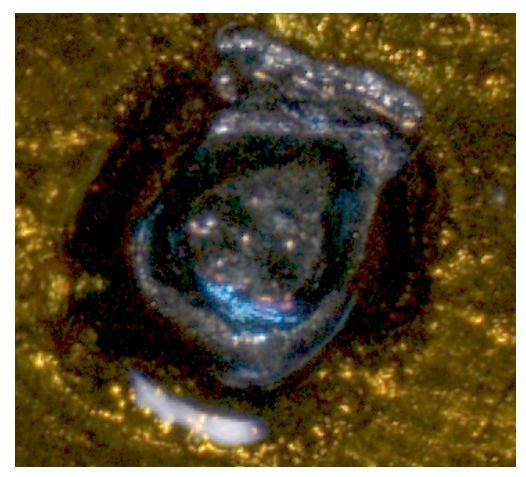

Figure 6. Picture of Mix 4 after spark test at 9.4 $\mathrm{J}$ at $0 \mathrm{Ohms}$ resistance. Scorch mark was apparent.

\subsection{DSC Analysis of the aged mixtures}

Differential scanning calorimetry is used to monitor phase change, measure thermal decomposition enthalpy and potentially identify the presence of reaction products that may form when NG and NC are mixed and then aged. The DSC behavior may change if any chemical reactions occur during the aging process. DSC measurements were performed on Mix 1 through 4 on the TA Instrument with pinhole vented sample holders and Mix 4 on the Setaram system with sealed sample holders. Figure 7 shows the Seteram DSC of Mix 4 (220-hour aging).

One exothermic feature is obvious in the figure with a $\mathrm{T}_{\max }$ of $203.1^{\circ} \mathrm{C}$ and $\Delta \mathrm{H}_{\text {exo }}$ of $3186 \mathrm{~J} / \mathrm{g}$. This is essentially the same DSC behavior of all the mixtures in this study. In the figure, there are also some very broad exothermic features with $\mathrm{T}_{\max }$ values around $300{ }^{\circ} \mathrm{C}$ and $400{ }^{\circ} \mathrm{C}$. These features were observed only in the Setaram profile and the Mix 1 TA Instruments DSC profile. They are not found in Mix 2, 3, and 4 TA Instruments DSC profiles. These features have not been assigned or distinguished from background issues. 


\begin{tabular}{|c|c|c|c|}
\hline INIISETARAM & Experiment : YS12-016 & 12 2:30:56 PM & NG/NC \#PCH-XIII-104-4 \\
\hline 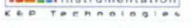 & Mass : $7(\mathrm{mg})$ & Procedure : $15-550 @ 10 \mathrm{cpm}$ & Wet Orange Gummy bear like \\
\hline Sensys $12 / 20 / 2012$ & Crucible : Incoloy 2012 & Zone name : $115-550 @ 10 \mathrm{cpm}$ & $\begin{array}{l}\text { Hsu_Montgomery } \\
\text { UHPN2 }\end{array}$ \\
\hline
\end{tabular}

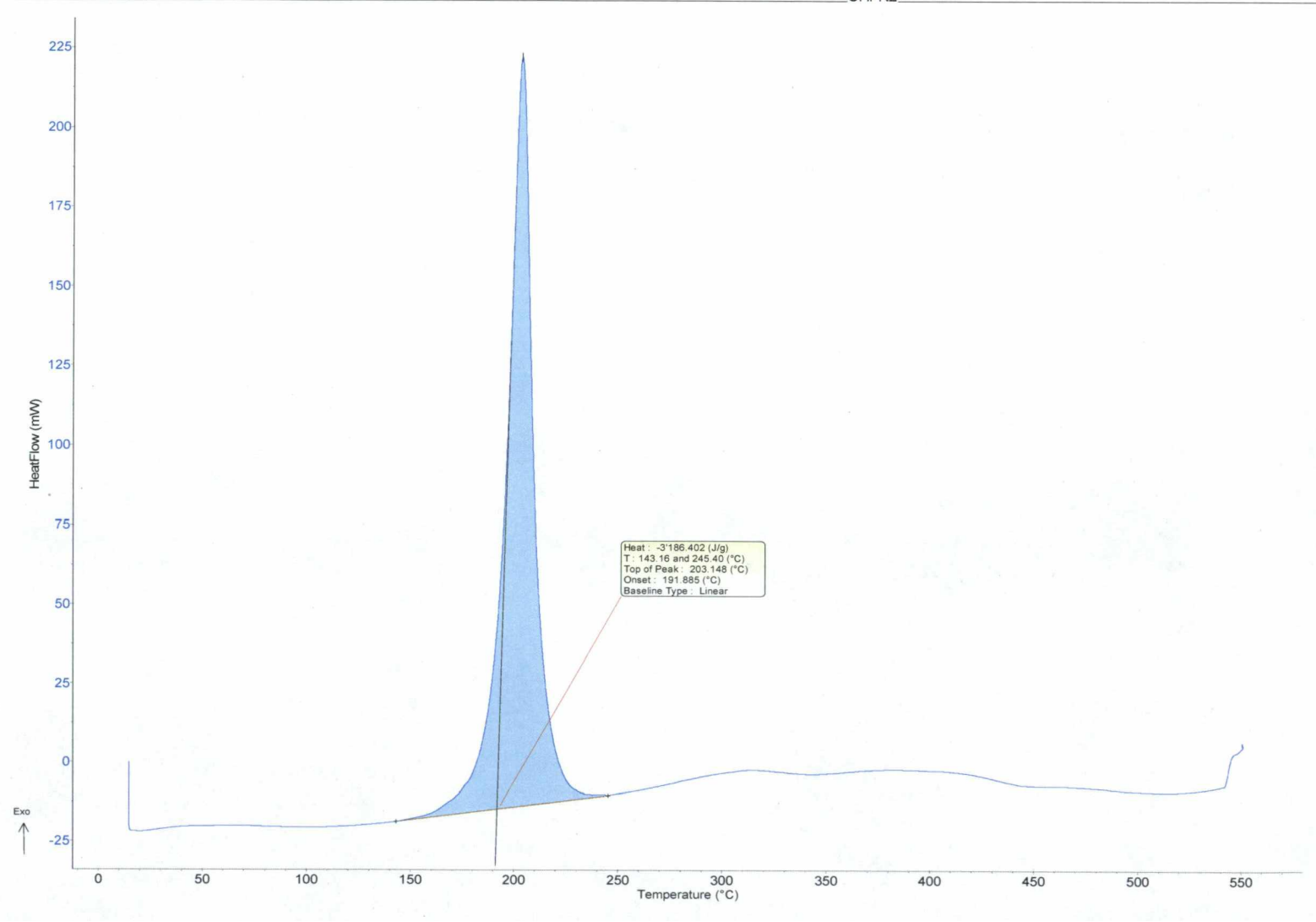

Figure 7. DSC of NG/NC Mix 4 by Setaram System with sealed sample holder

Table 4 shows the DSC data from the TA Instrument of all the mixtures. The onset and $\mathrm{T}_{\max }$ are in good agreement for Mix 1,2 and 3. There is a slight shift toward higher temperature for this exothermic feature shown in Mix 4. The enthalpies are in reasonable agreement for Mix 2, 3 and 4. Mix 1 shows a lower heat flow by about $20 \%$ compared to the other mixtures. Also the heat flow for Mix 4 is significantly lower measured by the TA Instruments DSC compared to the heat flow measured by the Setaram DSC. All the DSC profiles are attached in Appendix 1.

Table 4: DSC Test Result Summary for 4 NG/NC Mixtures from TA Instrument DSC (pinhole sample holder)

\begin{tabular}{|c|c|c|}
\hline Sample ID & Age, $\mathrm{h}$ & Onset $\mathrm{T},{ }^{\circ} \mathrm{C} / \mathrm{T}_{\max },{ }^{\circ} \mathrm{C}(\Delta \mathrm{H}, \mathrm{J} / \mathrm{g})$ \\
\hline Mix 1 & 4 & $182.22 / 203.17,(799.3)$ \\
\hline Mix 2 & 28 & $182.23 / 202.32,(1077)$ \\
\hline Mix 3 & 76 & $181.53 / 202.71,(947.9)$ \\
\hline Mix 4 & 220 & $178.61 / 209.09,(911.9)$ \\
\hline
\end{tabular}




\subsection{NMR Analysis of aged mixtures}

The NG/NC mixtures were also examined by ${ }^{1} \mathrm{H}$ NMR. Figure 8 shows the NMR spectra of NG (with $1 \% 2$ NDPA), pure NC, Mix 1 and Mix 2 taken in $\mathrm{CD}_{3} \mathrm{CN}$ as solvent.

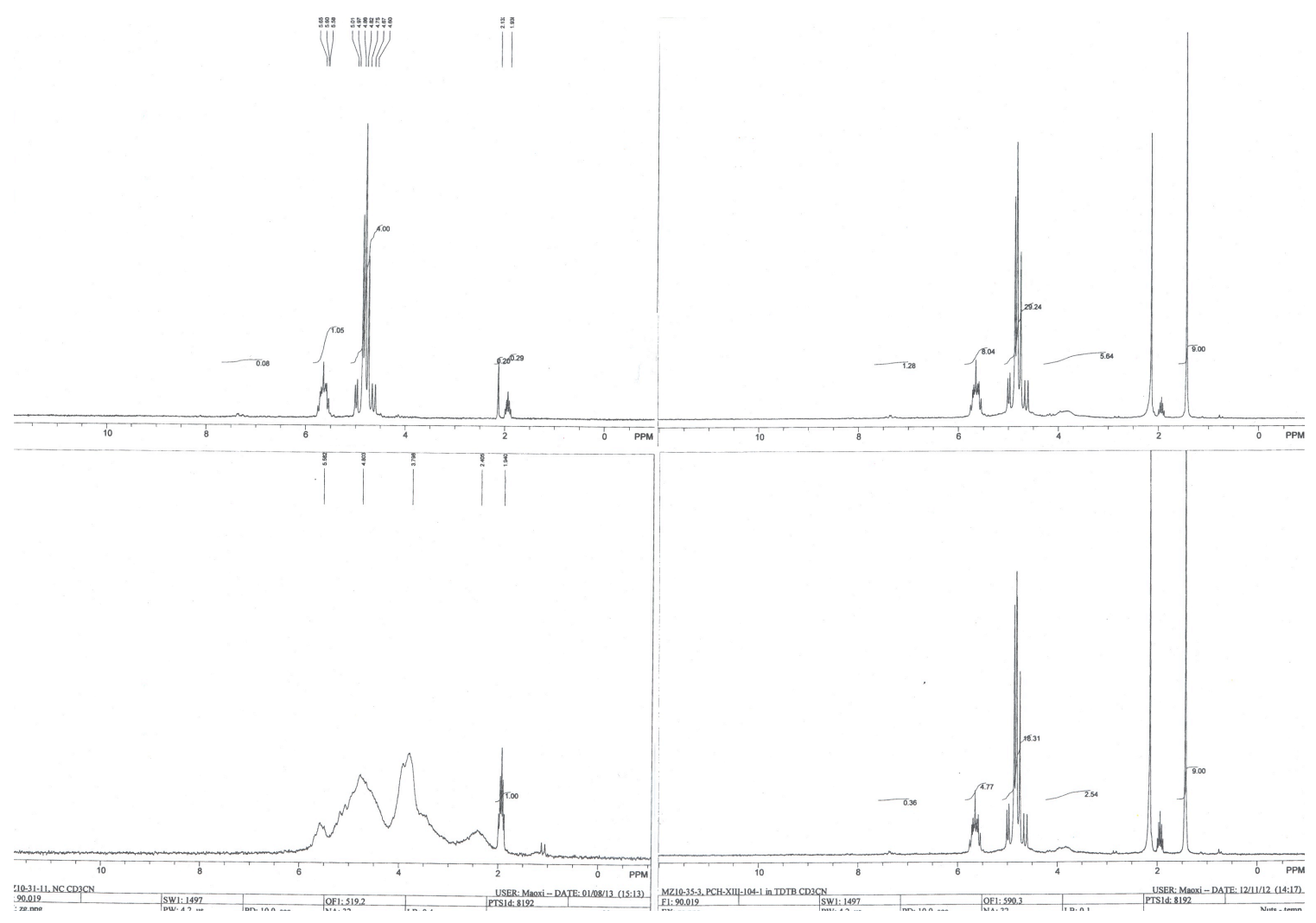

Figure 8. NMR spectra: top left-NG; bottom left-NC; top right-Mix 2; bottom right Mix 1

The figure shows the ${ }^{1} \mathrm{H}$ NMR spectrum of NG on the top left. Species identified are: NG (multiplets at 4.8 and $5.6 \mathrm{ppm}$ ), 2-NDPA (barely visible multiplets at $7.3 \mathrm{ppm}$ ) and solvent residual features around $2 \mathrm{ppm}$. The figure shows the ${ }^{1} \mathrm{H}$ NMR spectrum of NC on the bottom left. Species identified are: NC (series of broad features from $2 \mathrm{ppm}$ to $6 \mathrm{ppm}$ ) and solvent residual features around $2 \mathrm{ppm}$. The figure shows Mix 1 and Mix 2 on the right side. The prominent species are: NG multiplets centered around 4.8 and $5.6 \mathrm{ppm}$, TDTB (to sharp features at 1.4 and $2.1 \mathrm{ppm}$ ) and solvent residual species. Some features that correspond to $\mathrm{NC}$ are barely seen at $\sim 4.0 \mathrm{ppm}$, as well as 2-NDPA around $7.3 \mathrm{ppm}$. Both Mix 1 and Mix 2 are essentially the same. The NMR spectra are attached in the Appendix 2.

In the preparation of the NMR samples, the NG was weighed out and dissolved in a solution containing TDTB as an internal standard. The integrated area of the TDTB was used to evaluate the amount of NG in the sample as indicated by the integrated area of the NG multiplets in the spectrum. Because of the overlap of the NG and $\mathrm{NC}$ species, the actual integration of the multiplets at 4.8 and $5.2 \mathrm{ppm}$ have contribution from $\mathrm{NC}$ due to the overlapping spectral features as indicated in the spectra of the two pure compounds shown in Figure 8 . Therefore the data in Table 8 are not particularly good for absolute quantitation. The \%NG indi- 
cates the technique overestimates the concentration of the NG due to this spectral overlap. All values except for $105.8 \%$ are over $110 \%$. However, the data can be used for assessment of the relative change of NG over time. The average values of the percentage NG estimated from the integration areas are: Mix 1, $113.6 \pm$ $0.2 \%$; Mix 2, $114.9 \pm 2.4 \%$; Mix 3, $114.1 \pm 0.1 \%$; Mix 4, $111.2 \pm 4.7 \%$; Mix all averaged, $113.3 \pm 2.7 \%$. All these values are the same within experimental error based on the replicate measurements (the error in replicate measurements is no better than $4.7 \%$ ).

Table 5. Weight of NG derived from ${ }^{1} \mathrm{H}$ NMR spectra of Mix 1, 2, 3 and 4 (TDTB used as internal standard) compared to actual weighed amounts

\begin{tabular}{|c|c|c|c|c|c|}
\hline Mix & Trial & Weight, $\mathrm{mg}^{\mathrm{a}}$ & Weight NG, $\mathrm{mg}^{\mathrm{t}}$ & Integrated NG, mg & \% $\mathrm{NG}^{\mathrm{c}}$ \\
\hline $1^{\mathrm{d}}$ & $1^{\mathrm{e}}$ & 45.6 & 36.8 & 41.7 & 113.3 \\
\hline $1^{\mathrm{d}}$ & $2^{\mathrm{f}}$ & 52.4 & 42.2 & 48.0 & 113.7 \\
\hline $1^{\mathrm{d}}$ & $3^{\mathrm{g}}$ & 50.9 & 41.0 & 46.6 & 113.7 \\
\hline $2^{\mathrm{h}}$ & $1^{\mathrm{i}}$ & 56.1 & 45.5 & 52.1 & 114.5 \\
\hline $2^{\mathrm{h}}$ & $2^{\mathrm{j}}$ & 44.7 & 36.2 & 42.5 & 117.4 \\
\hline $2^{\mathrm{h}}$ & $3^{\mathrm{k}}$ & 73.9 & 60.0 & 67.7 & 112.8 \\
\hline $3^{\mathrm{l}}$ & $1^{\mathrm{m}}$ & 52.2 & 42.0 & 47.9 & 114.0 \\
\hline $3^{\mathrm{l}}$ & $2^{\mathrm{n}}$ & 126.6 & 101.8 & 116.1 & 114.2 \\
\hline $3^{\mathrm{l}}$ & $3^{\mathrm{o}}$ & 76.0 & 61.1 & 69.8 & 114.4 \\
\hline $4^{\mathrm{p}}$ & $1^{\mathrm{q}}$ & 60.0 & 48.6 & 55.6 & 105.8 \\
\hline $4^{\mathrm{p}}$ & $2^{\mathrm{r}}$ & 78.8 & 68.7 & 72.7 & 113.5 \\
\hline $4^{\mathrm{p}}$ & $3^{\mathrm{s}}$ & 86.7 & 70.2 & 79.7 & \\
\hline
\end{tabular}

a. weight of sample; b. weight through integration compared to TDTB standard; c. integrated weight/measured weight; d. sample PCH-XIII-104-2; e. notebook number MZ10-35-2; f. notebook number MZ10-35-1; g. notebook number MZ10-35-3; h. sample PCH-XIII-104-2; i notebook number MZ10-35-10; j. notebook number MZ10-35-11; k. notebook number MZ10-35-12; 1. Sample number PCH-XIII-104-3; m. notebook number MZ10-35-30; n. notebook number MZ10-35-31; o. notebook number MZ10-35-32; p. sample number PCH-XIII-104-4; q. notebook number MZ10-35-40; r. notebook number MZ10-35-41; s. notebook number MZ10-35-42; t. weight of sample multiplied by NG/NC ratio from Table 1.

\subsection{Visual analysis of the NG/NC mixture}

NG/NC mixtures have been noted to evolve bubbles over time. This was first noted in the original mixing experiments in 2010 [9]. Bubble growth has also been documented in the previous study where bubbles appeared within 23 hours of mixing. The concentration of bubbles continued to increase during the aging process.

Bubble formation has been observed in the current mixtures. Figure 9 shows a photograph of Mix 1 after 23 hours of aging. Clearly bubbles are seen throughout the material.

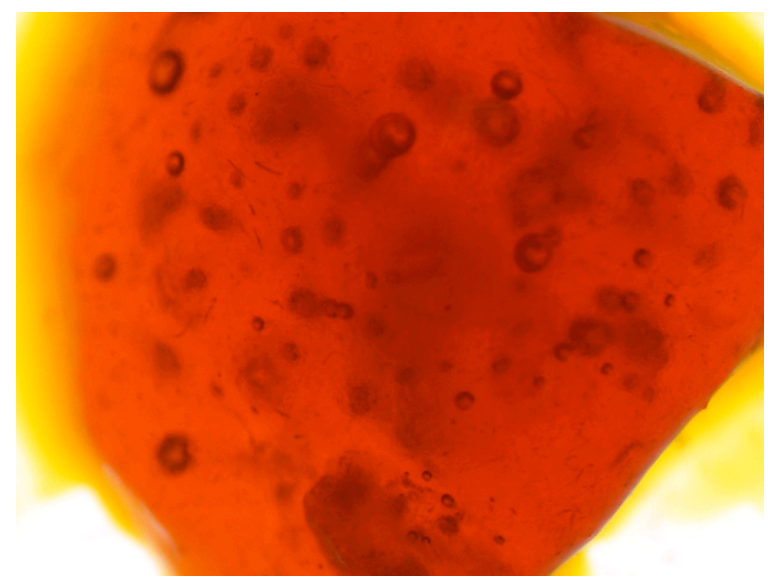


Figure 9. Optical photograph of Mix 1, 23 hours after mixing.

\section{DISCUSSION}

\subsection{Effect of aging on NG/NC SSST testing results.}

This study was performed to determine if aging affects SSST properties. A previous report [6] demonstrated a NG/NC mixture became more impact sensitive with age. This increase in sensitivity was large enough to warrant further examination into the phenomenon and broaden the study to other explosive sensitivity parameters, such as friction, spark and thermal.

Impact Sensitivity. The initial results of impact testing of NG/NC (on sand paper) indicate a material that is more sensitive than PETN. The absolute values of these results depend upon the anvil configuration in the drop hammer experiment. For the bare anvil configuration, which is the standard configuration for testing liquids at LLNL, the $\mathrm{DH}_{50}$ value is $7.6 \mathrm{~cm}$. $\mathrm{NG} / \mathrm{NC}$ is viscous enough that sandpaper can also be used, which is the standard configuration for testing solids at LLNL. The $\mathrm{DH}_{50}$ value is $4.7 \mathrm{~cm}$. This difference can be explained by the grit of the sandpaper providing more sites than a flat bare anvil for reactions to occur.

Upon aging, the NG/NC becomes more sensitive when sandpaper is used to hold the sample in place. This trend is in agreement with a previous study on an 80/20 mixture of NG/NC [6]. In that study, only the impact sensitivity was measured as a function of aging. Over a period of 4 hours, the mixture became almost twice as sensitive. The sensitivity continued to change, and after 4 days, the $\mathrm{DH}_{50}$ value was $2.0 \mathrm{~cm}$, the same as Mix 4, which was aged for 9 days. When measured on a bare anvil, the NG/NC mixture became less sensitive to impact, rising to about $15 \mathrm{~cm}$ after one day of aging. Tests done in $2011 \mathrm{on} \mathrm{NG/NC} \mathrm{mixture} \mathrm{[7]}$ on bare anvil showed higher $\mathrm{DH}_{50}$ values than $15 \mathrm{~cm}$, probably less air bubbles were formed during the mixing of the formulation. More study is needed to quantify the effect of air bubbles on the impact sensitivity.

Friction Sensitivity. The BAM friction results in Table 3 indicate initially, the NG/NC mixture is less sensitive than PETN. This also was the conclusion of the previous testing [6]. Upon aging however, it appears that the material becomes somewhat less sensitive, going from 1/10@8.4 kg to 1/10@12 kg.

Spark Sensitivity. Spark sensitivity tests show the NG/NC mixture was not spark-sensitive; no spark initiation was observed when energy was set at below 9.4 Joules.

Thermal Sensitivity. The DSC of NG exhibits a lone exothermic feature (Setaram Sensys data) with a $\mathrm{T}_{\max }=$ $197.4{ }^{\circ} \mathrm{C}$ and $\Delta \mathrm{H}_{\mathrm{exo}}=3.415 \mathrm{~J} / \mathrm{g}$ [8]. The DSC of pure $\mathrm{NC}$ also exhibits a lone exothermic feature (TA Instrument data) with a $\mathrm{T}_{\max }=208.7^{\circ} \mathrm{C}$ and $\Delta \mathrm{H}_{\text {exo }}=2582 \mathrm{~J} / \mathrm{g}$ [9]. The DSC of Mix 1 exhibits a $\mathrm{T}_{\max }$ between the 2 components. Likewise, Mix 2 and 3 exhibit the same prominent feature. Only Mix 4 shows a shift in this $\mathrm{T}_{\max }$ value. However, the $\mathrm{T}_{\max }$ determined by the Setaram system is $203{ }^{\circ} \mathrm{C}$ matching Mix 1-3. These DSC values show that the NG dominates the DSC behavior. There could be other species present that are a result of the NG and $\mathrm{NC}$ reacting chemically, but it is difficult to determine based on the dominance of the NG in the mixture and the overlap of the DSC features. There are higher temperature very broad exothermic features in the TA Instruments DSC profile of Mix 1 (see Appendix) and the Setaram Sensyn DSC profile of Mix 4 (see Figure 7). The lack of these features in the other profiles makes their identification dubious at best.

\subsection{Speculation on the Cause of Sensitivity Changes of NG/NC upon Aging}

The previous study on NG/NC aging proposed that changes observed in material's impact sensitivity was due to bubbles forming over time, hypothesed that these bubbles provide sites of reactivity, at least in the drop 
hammer test. Other mechanisms were not eliminated in that study, and, in an effort to confirm or disprove these mechanisms, the compositional behavior of the mixtures were examined by NMR spectroscopy in this study. Unfortunately, the NMR approach did not provide enough information to determine whether chemical changes are occurring. Both the limitations in the precision and sensitivity of this technique made it insufficient to discern changes and the overlap of the spectral features of the component inhibited detection of reactive species, if any. The NMR data indicates no change is occurring in the major feature that is observable under the experimental conditions.

Likewise, the DSC data also exhibit little or no evidence that there are that there are reactive products that might be thermally active. This technique suffers from the same problems as the NMR technique, close overlap of the component materials and no prominent reaction products.

Regardless of the NMR and the DSC results, something is causing the change in sensitivity to impact as well as bubble formation. Figure 9 clearly shows a dramatic example of bubble formation in Mix 1 after 23 hours. Similar bubble formation was seen in all the other mixtures. These issues are important because the change in sensitivity can affect the development of safe handling procedures and the bubble formation can affect rheological properties, such as density.

Figure 10, taken from the previous study [6], is of a single sample of the NG/NC mixture photographed at different aging times. The left side photograph is the freshly prepared sample; other than the voids where no material is located, no bubbles are obvious. The middle photograph is the mixture after 24 hours and some bubble formation is apparent. The right side photograph is the mixture after 4 days showing even more bubbles. Even though Figure 9 and Figure 10 exhibit different rheology, they both document the bubble formation.

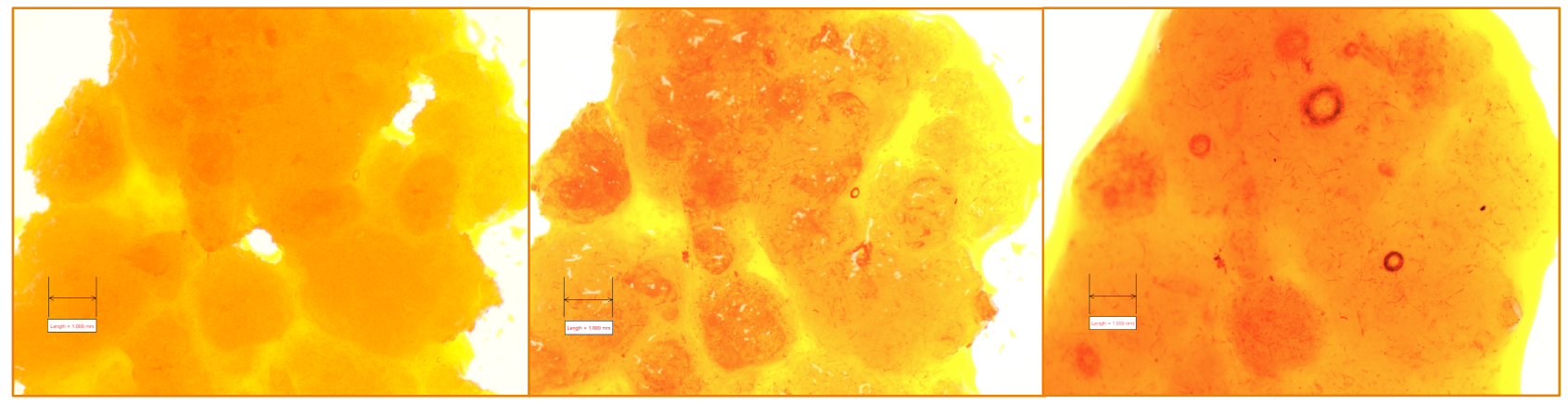

Figure 10. Photographs of NG/NC mixture from reference 6; the left side image was taken soon after preparation, middle image taken after 23 hours, and the right side image taken after 4 days.

The bubble argument uses the premise that increasing bubble formation during the aging process produces an increasing number of localized sites for reaction. Therefore the older the sample, the more reactive the sample, and the test results will show an increasing sensitivity. Table 3 verifies this in the impact data taken on the drop hammer equipment configured with sandpaper to hold the sample in place. This is also seen in impact data of the previous study also taken on the drop hammer equipment configured with sandpaper [6]. However, this theory does not necessarily explain the impact data taken on the drop hammer configured using bare anvil for staging the sample. Table 3 shows this data also, and in this case, the mixture shows decreasing sensitivity with increasing bubble formation.

These opposing trends in data can possibly be better explained by dissolution effects. NG is a liquid and NC is a porous, powdered solid. When mixed, the NG slowly dissolves NC, eventually leading to a e homogenous liquid system with trapped bubbles. The photograph in Figure 10 of the freshly mixed material shows some of the heterogeneity. As the sample ages, the liquid nature begins to spread out, the darker color of the NC begins to diffuse into the NG. This is more dramatically seen in the 4-day sample in Figure 10 and much more dramatically in Figure 9, where the red color is almost homogeneous throughout. 
The freshly mixed sample is a heterogeneous mixture of liquid NG evenly wetting the solid NC particles. Upon mechanical impact, the solids may provide localized sites for reactions. As the NC dissolves in the $\mathrm{NG}$, these sites go away, and therefore when using the bare anvil, the material becomes less sensitive, as seen in the results in Table 3. When testing using the sandpaper, however, the original material derives most of the sites for reaction based on the grit of the sandpaper. As the NC dissolves into the NG, the system becomes increasingly homogeneous, but still has the discontinuities from sandpaper, so sensitivity increases, as seen in the results in Table 3.

\section{CONCLUSIONS}

Four NG/NC mixtures were prepared and tested after various aging periods for their sensitivities to various stimuli with drop hammer (drop weight) system, BAM friction test system, ABL spark test system and DSC. ${ }^{1} \mathrm{H}$ NMR was also used to detect and identify potential chemical reaction products occurring within the mixture.

The NG/NC mixtures exhibited the following upon aging:

1. Impact sensitivity increased with age when the drop hammer testing was configured with 120 -grit $\mathrm{Si} /$ carbide wet/dry sandpaper.

2. Impact sensitivity decreased with age when the drop hammer testing was configured with only a bare anvil to hold the sample in place.

3. BAM friction sensitivity showed a slight increase with aging.

4. The material was not spark-sensitive as measured by ESD..

5. DSC showed no apparent additional species different than the component materials.

6. NMR showed no apparent formation of reaction products between the two components.

7. Bubble formation was observed upon aging as seen previously.

Bubble formation and solubility are used to speculate on the effects of aging on the sensitivity of the NG/NC mixture.

\section{NOMENCLATURE}

$\begin{array}{ll}\text { ABL } & \text { Allegheny Ballistics Laboratory (Rocket Center, West Virginia) } \\ \text { BAM } & \begin{array}{l}\text { Bundesanstalt für Materialforschung und -prüfung (Berlin, Germany) } \\ \text { drop hammer values }\end{array} \\ \text { DH } & \text { Differential scanning calorimetry } \\ \text { DSC } & \text { Explosives Research Laboratory (of the former U.S. National Defense Research Committee.) } \\ \text { ERL } & \text { Cyclotetramethylenetetranitramine } \\ \text { HMX } & \text { Nitrocellulose } \\ \text { NC } & \text { Nitroglycerine } \\ \text { NG } & \text { Nuclear magnetic resonance } \\ \text { NMR } & \text { Pentaerythritol tetranitrate } \\ \text { PETN } & \text { picofarad } \\ \text { pF } & \text { Cyclotrimethylenetrinitramine } \\ \text { RDX } & 1,3,5 \text {-triamino-2,4,6-trinitrobenzene } \\ \text { TATB } & \end{array}$

\section{REFERENCES}

1. Simpson, L. R. and Foltz, M.F., "LLNL Small-Scale Drop-Hammer Impact Sensitivity Test," UCRL-ID119665, 1995.

2. Dixon, W.J. and Massey, F.J., "Introduction to Statistical Analysis, 2nd ed., McGraw-Hill, New York, pp 318$327,1957$. 
3. Dixon, W.J., "The Up and Down Method for Small Samples," J. Am. Statistical Assoc., 60, pp 967-978, 1965.

4. Simpson, L.R. and Foltz, M.F., "LLNL Small-Scale Friction Sensitivity (BAM) Test," UCRL-ID-124563, 1996.

5. Simpson, L.R. and Foltz, M.F., "LLNL Small-Scale Static Spark Machine: Static Spark Sensitivity Test," UCRL-ID-135525, 1999 .

6. Hsu. P.C., Hust, G. and Schmidt, R., LLNL-TR-598132, November 2, 2012.

7. LLNL Drop hammer log book, volume 24, pages 69 to 73, 2011.

8. R. D. Schmidt, Setaram Sensys output file YS11-022, 2/1/2011.

9. HE Reference Guide

10. R. D. Schmidt, personal communication.

\section{APPENDIX 1. SMALL-SCALE SAFETY AND THERMAL TEST DATA FOR NG/NC MIXTURES}

\section{APPENDIX 2. NMR SPECTRA OF NG/NC MIXTURES, COMPONENTS, AND STANDARDS.}

